\section{The European Association for Bronchology and Interventional Pulmonology (EAB) Is on Course}

We have a lift-off! One year after inauguration, inscription and acknowledgement of the EAB as non-profit association, the EAB is gaining shape and attracts a quickly increasing number of members. Not only is the EAB perceived as a forum for scientific and personal communication, also the advantage of having an indexed journal with a broader spectrum of topics and increasing impact, included within a very competitive membership fee, is appreciated. In addition Karger publishers are offering a discount for members on all their publications with related topics.

As, due to the administrative procedures, there has been some delay, membership fees originally considered for 2002 will be transferred to 2003, but 2002 back issues of Respiration will be provided to the subscribers.

Further initial objectives have been achieved:

The cooperation with the ERS has proven successful. Last year at the conference in Stockholm, the EAB organized a workshop on imaging procedures with the main focus on ultrasound by transthoracic, endoesophageal and endobronchial approaches. Additional lectures on most recent progress in radiological imaging and new devices for navigation opened a broad perspective for future diagnostic and therapeutic procedures in bronchoscopy.

These state-of-the-art lectures generated tremendous interest, and will therefore be published as a continuing series of 6 articles in the upcoming issues of Respiration. The first article 'Transthoracic Ultrasound' by F. Herth and H.D. Becker appears in this issue of Respiration. The following articles will each appear in the following 5 issues of the current volume: 'Endobronchial Ultrasound' by F. Falcone, 'Esophageal Ulrasound' by M. Krasnik, 'Electronic Navigation by Magnetic Fields' by Y. Schwarz, 'Advanced Thoracic Imaging' by A. Ernst, and 'Bronchoscopy 2003 and Beyond' by H.D. Becker.

After the initial success, further topics for the second EAB workshop at the upcoming ERS congress in Vienna 2003 are being planned.
We encourage submission of high-quality original nonsolicited articles for the EAB section in the journal. It is our clear aim to become a leading publication in the area of interventional pulmonology worldwide.

As promotion of education and clinical practice of bronchology and related sciences is a primary goal of our activities, an increasing number of colleagues are asking for support in organizing courses and meetings under the auspices of the EAB.

Several international societies expressed their interest in cooperation with the EAB. As several members of the $\mathrm{EAB}$ are also members of these societies, common standards for diagnostic and therapeutic procedures have been developed or are currently under discussion.

The founders of the EAB are optimistic and confident that after its promising start the association will grow steadily by establishing local national branches. In addition, colleagues of neighboring countries and regions, such as Turkey and some Middle Eastern countries, already expressed their strong interest in becoming affiliate members. Some companies have already joined the association as well, as corporate members, as they are recognizing common objectives.

By now, Dear Reader, you are hopefully convinced of the interest of joining the EAB. But how do I go about becoming a member of this young and dynamic society, you may ask yourself? The easiest way is an on-line registration at www.karger.ch. Applications billing and shipping of Respiration all take place at the publisher's, S. Karger AG, Basel. The scientific secretariat, on the other hand, is currently in Heidelberg, Germany, where you will find both EAB president, H.D. Becker, and EAB secretary, F. Herth, always eager to plan further events and answer all the questions you may have relating to interventional pulmonology.

May the EAB prosper and bloom for many years to come!

H.D. Becker, Heidelberg

C.T. Bolliger, Cape Town

\section{KARGER \\ (C) 2003 S. Karger AG, Basel}

Fax +4161306 1234

E-Mail karger@karger.ch

www.karger.com
Accessible online at: www. karger.com/res 